$$
\text { CONf- } 960706 \ldots 21
$$

EFFECT OF THE HIGH FLUX ISOTOPE REACTOR BY THE NEARBY HEAVY LOAD DROP

\author{
S. J. Chang
}

Research Reactors Division

Oak Ridge National Laboratory

Oak Ridge, Tennessee

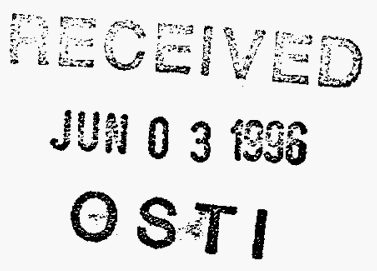

Presented at

American Society for Mechanical Engineers (ASME)

Pressure Vessels, Piping, and ICPVT-8 Conference

Montreal, Canada

July 22-26, 1996

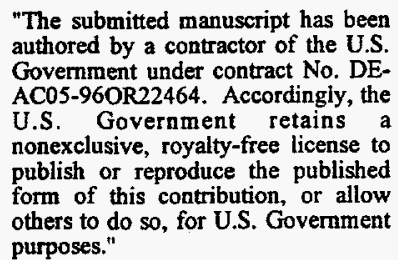

Prepared by the

Research Reactors Division

OAK RIDGE NATIONAL LABORATORY

Oak Ridge, Tennessee 37831

managed by

LOCKHEED MARTIN ENERGY RESEARCH CORP.

for the

U.S. DEPARTMENT OF ENERGY

under contract DE-AC05-96OR22464 


\section{DISCLAIMER}

Portions of this document may be illegible in electronic image products. Images are produced from the best available original document. 


\title{
Effect to the High Flux Isotope Reactor by the Nearby Heavy Load Drop'
}

\author{
S. J. Chang \\ Research Reactors Division \\ Oak Ridge National Laboratory \\ Oak Ridge, Tennessee 37831
}

\begin{abstract}
In this calculation, GE-2000 cask of $25,000 \mathrm{lbs}$ is assumed to drop from a height of 20-ft above the bottom of the High Flux Isotope Reactor (HFIR) pool slab with end velocity of $430 \mathrm{in} / \mathrm{sec}$ at the loading station. The consequences of the dynamic impact to the bottom slab of the pool and to the nearby HFIR reactor vessel are analyzed by applying ABAQUS computer code. The results show that both HFIR vessel structure and its supporting legs are subjected to elastic disturbances only and will not be damaged. The bottom slab of the pool will be damaged. The plastic strain that will cause failure to the concrete slab at the point of impact extends a distance approximately half of the slab thickness of 36 inches. The plastic strain of failure for concrete is assumed to be $0.45 \%$. The velocity response spectrum at the concrete slab next to HFIR vessel as a result of the impact is also obtained. The maximum spectral velocity is approximately $10 \mathrm{in} / \mathrm{sec}$. It is approximately equal to the maximum magnitude of the Oak Ridge velocity spectrum formulated recently with $0.26 \mathrm{~g}$ peak ground acceleration and $5 \%$ damping. However, the peak ground acceleration that is associated with the impact generated response spectrum curve can be as much as $20 \mathrm{~g}$. The high frequency acceleration waves are generated in impact problems. It is concluded that the damage caused by heavy load drop at loading station is controlled by the slab damage. The damage of slab will not be severe enough to cause the leakage of pool water.
\end{abstract}

\subsection{INTRODUCTION}

The purpose of this calculation is to evaluate the consequences of an accidental drop of a heavy container on the floor of the High Flux Isotope Reactor (HFIR) pool. The analysis is to estimate whether the impact caused by the drop may have the magnitude that is intense enough to damage the HFIR reactor vessel and its supporting legs. The total weight of the container and the contents is approximately $25,000 \mathrm{lbs}$.

The problem is simplified to an equivalent twodimensional plane strain model. The model consists of the

\footnotetext{
'Based on work performed at Oak Ridge National Laboratory, managed by Lockheed Martin Energy Research Corporation., for the U.S. Department of Energy under contract DE-AC05960R22464. Accordingly, the U.S. government retains a nonexclusive, royal-free license to publish or reproduce the published form of this contribution, or allow others to do so, for U.S. government purposes.
}

concrete slab and the concrete wall of the pool, the idealized heavy load, the HFIR vessel and its supporting leg. The total heavy load is idealized to an equivalent two-dimensional load. The two dimensional load is assumed to be the total load divided by the width of the container. The resulting twodimensional load is further reduced to $50 \%$. The $50 \%$ reduction is assumed because of the three-dimensional effect of the reinforced concrete slab. To construct a twodimensional model, the total weight of the HFIR vessel is assumed to be distributed across the width of the lower portion of the vessel of $33 \mathrm{in}$. It is a conservative estimate of the two-dimensional weight of the vessel. The vessel weight is further approximately modeled by four lumped mass points attached along the vertical axis of the vessel. The lower vessel and the supporting legs are idealized by using equivalent steel beam elements.

The reinforced concrete slab and wall are assumed to be monolithic and homogeneous piece of solid. The solid is equally strong in tension as in compression. All the numerical calculations are performed by using ABAQUS computer code. Concrete failure strain is assumed to be $0.45 \%$ (ref. 1). Concrete density is assumed to be $145 \mathrm{lb} / \mathrm{ft}^{3}$ and concrete yield stress is assumed to be $4 \mathrm{ksi}$ (ref. 1). The effect of the pool water that surrounds the HFIR vessel is neglected in the analysis.

Similar to the two-dimensional assumption made in this calculation, the same simplified assumption was also made in an extensive NUREG report on drop and seismic evaluations for $\mathrm{H}$. B. Robinson and Vermont Yankee nuclear power plants (ref. 2). The present calculation is an accident analysis. The 84-day yield stress of $4 \mathrm{ksi}$ is used. The maximum compressive stress can be even higher. These values can be confirmed by data shown in Ferguson's book (pp. 10 and 11, ref. 1) in which several concrete strength test results are presented. Furthermore, on p. 9 of ref. 1, the maximum concrete allowable strain is specified.

\subsection{CALCULATION INPUT}

1. HFIR vessel dimension and weight distribution

$\begin{array}{ll}\text { Vessel inner diameter } & -6 \mathrm{in} . \\ \text { Vessel wall thickness } & -3 \mathrm{in} . \\ \text { Lower vessel diameter } & -33 \mathrm{in} . \\ \text { Lower vessel wall thickness } & -1.5 \mathrm{in} .\end{array}$


Vessel head weight

Vessel proper

$$
\begin{aligned}
& -28,000 \mathrm{lbs} \\
& -69,000 \mathrm{lbs}
\end{aligned}
$$

Assume vessel $69,000 \mathrm{lbs}$ weight is distributed uniformly along the axis and is idealized by four mass points to be distributed through a thickness of $33 \mathrm{in.}$ of the diameter of the lower vessel.

\section{Heavy load distribution}

The GE-2000 container weight is calculated from the following:

Total weight

Container width

Container height

Linear-weight

$50 \%$ for 3 -dimension

$25,000 \mathrm{lbs}$

$38.50 \mathrm{in.}$

$71.00 \mathrm{in}$. $25,000 / 38.50=649 \mathrm{lb} / \mathrm{in}$. $324 \mathrm{lb} / \mathrm{in}$. $0.84 \mathrm{lb} \cdot \mathrm{s}^{2} / \mathrm{in}^{2}$

\section{HFIR vessel supporting column}

$8^{\prime \prime} \phi$ Schedule 160 pipe supporting column from the handbook ANSI/ASME B36-10M·1985 has:

Outside diameter

-8.625 in.

Wall thickness

Weight per foot

-0.906 in.

$-74.69 \mathrm{lb} / \mathrm{ft}$

XXS (double extra strong)

Manual of Steel Construction, 8th edition, AISC, 1990

\begin{tabular}{|c|c|}
\hline$F_{y}$ & - 36 ksi double extra \\
\hline Area & -21.3 in. $^{2}$ \\
\hline Wall thickness & $\begin{array}{l}-0.875 \text { in. } \\
-162 \text { in }^{4}\end{array}$ \\
\hline
\end{tabular}
for 8" $\phi$ column shows:

The two-dimensional input values:

$$
\begin{array}{ll}
\text { Area }-21.3 \text { in. }{ }^{2} / 33 \text { in. } & =0.645 \text { in. } \\
\text { Ix }-162 \text { in. }{ }^{4 / 33} \text { in. } & =4.9 \text { in. }^{3} \\
\text { ly }-4.9 \text { in. }^{3} & \\
\text { Ir }- & 9.6 \text { in. }^{3}
\end{array}
$$

\section{$4 \quad$ Material constants}

Vessel and supporting legs made of high strength steel:

Young's modulus

Poisson's ratio

Yield stress

Ultimate stress

Material density

$$
\begin{aligned}
& -29 \times 10^{3} \mathrm{ksi} \\
& -0.3 \\
& -36 \mathrm{ksi} \\
& -58 \mathrm{ksi} \\
& -0.284 \mathrm{lb} / \mathrm{in}^{3} \\
& 0.000735 \mathrm{lb} \cdot \mathrm{s}^{2} / \mathrm{in}^{4}
\end{aligned}
$$

High strength concrete:

$\begin{array}{ll}\text { Young's modulus } & -4.5 \times 10^{3} \mathrm{ksi} \\ \text { Poisson's ratio } & -0.15 \\ \text { Yield stress } & -4.0 \mathrm{ksi} \\ \text { Ultimate stress } & -6.0 \mathrm{ksi} \\ \text { Material density } & -0.084 \mathrm{lb} / \mathrm{in}^{3} \\ & 0.000218 \mathrm{lb} \cdot \mathrm{s}^{2} / \mathrm{in}^{4}{ }^{4} \\ \text { Failure strain } & -0.45 \%\end{array}$

\subsection{COMPUTATION AND ANALYSIS}

The impact solution of the drop problem by using ABAQUS computer code makes the assumption that the reinforced concrete is homogenous and capable to carry compressive stress as well as tensile stress. The twodimensional finite element model is shown in Fig. 1. The GE-2000 cask and the fuel contained in the cask weight approximately $25,000 \mathrm{lbs}$. It is assumed to be dropped from a height of $20 \mathrm{ft}$ above the bottom floor of the pool. This produces an end velocity of $430 \mathrm{in} . / \mathrm{sec}$ at the moment of impact to the concrete slab.

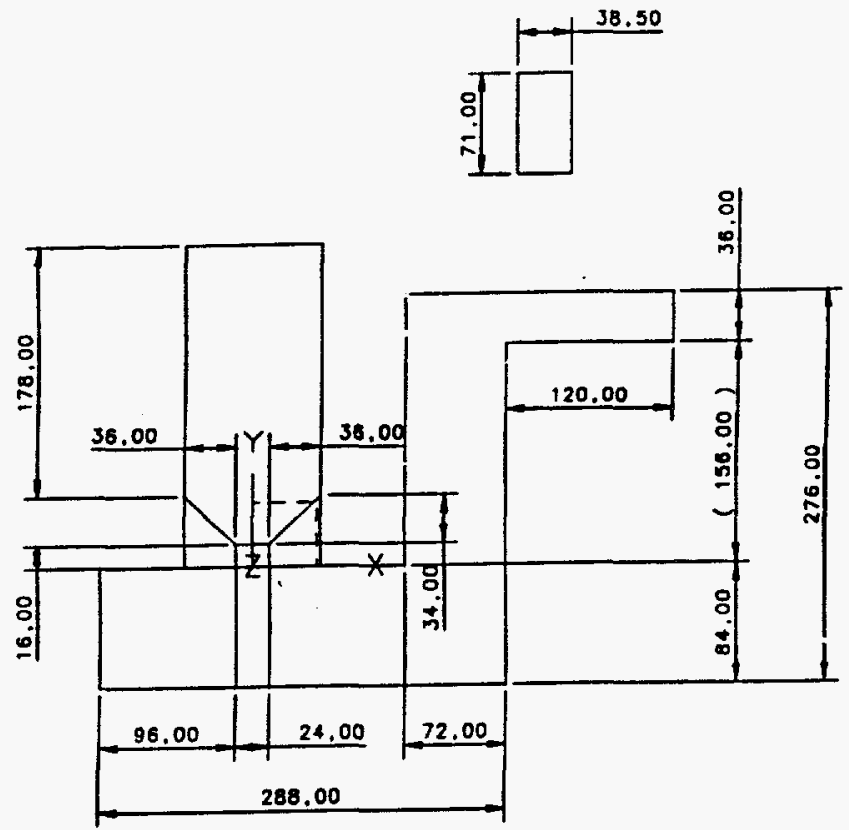

Fig. 1. Two-dimensional model of HFIR reactor vessel subjected to dynamic impact caused by drop of GE-2000 cask. The cask weighs 25,000 lbs. The weight drops from a height of $20 \mathrm{ft}$ that generates the end velocity of $430 \mathrm{in} . / \mathrm{sec}$ at the moment it impacts on the bottom of the pool.

The two-dimensional model shown in Fig. 1 includes concrete slab, concrete wall, HFIR vessel, and supporting legs. The critical parts of the structure exhibiting maximum stresses are the lower vessel wall and the supporting legs. The stress distribution for either part is obtained. 
1. Two-dimensional impact solution

a. Displacement time history of the heavy load

Figure 2 shows the time history for the vertical displacement of the cask after it begins to contact the floor of the pool. It is seen that the impact begins at time equal to 0 sec and the object remains in contact to the slab until time equal to $0.004 \mathrm{sec}$. After $0.004 \mathrm{sec}$, the object begins to bounce back and separates from the slab.

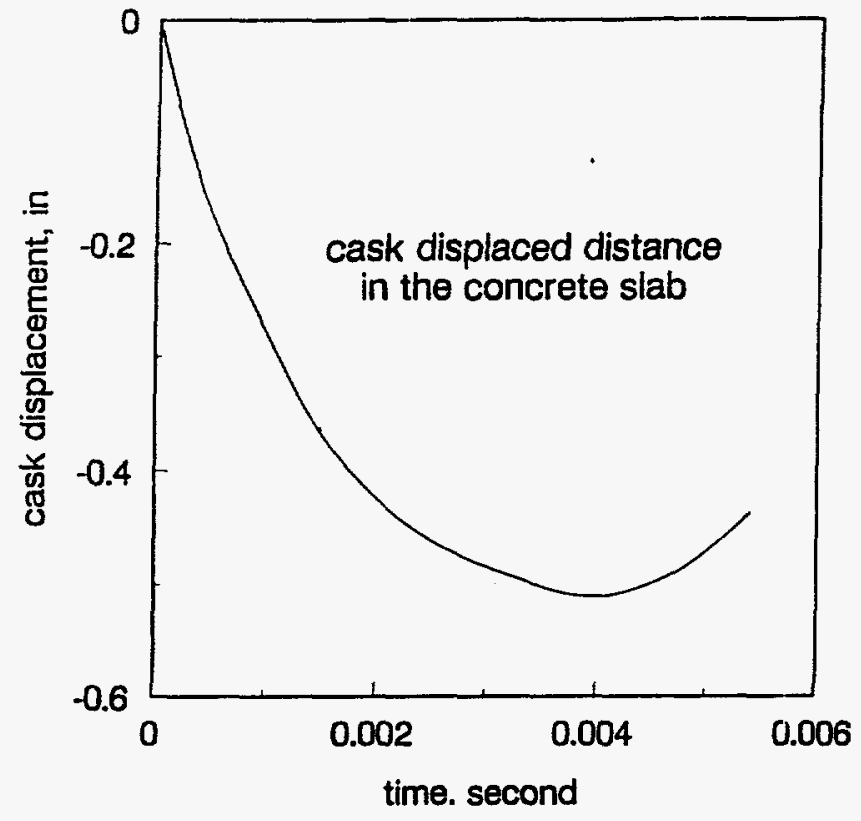

Fig. 2. Time histories of the displaced distance of the GE cask after it begins to contact the bottom of the pool. The maximum distance of cask penetration to the concrete slab is approximately 0.5 inch.

b. Stress and strain distributions at time equal to 0.054 $\underline{\text { sec }}$

The maximum amount of plastic strain printed into the slab is shown in Fig. 3 at the instant of time equal to 0.0054 sec. If the concrete failure strain is assumed to be $0.45 \%$, then the slab would have been damaged approximately half of its thickness.

\section{c. Time history solution of the stresses at lower vessel wall and at supporting legs}

This section gives an estimate of the possible maximum stresses that may be generated at the lower reactor vessel wall and at the supporting legs. The results show that the stresses are within the elastic range and will not be damaged

Figures $4 \mathrm{a}$ and $4 \mathrm{~b}$ show the stress vs time curves of the lower vessel wall and of the supporting legs, respectively. The maximum numerical values and time instants are tabulated in the following table.

\begin{tabular}{|c|c|c|c|}
\hline Parts name & $\begin{array}{r}\text { time, } \\
\text { sec }\end{array}$ & $\begin{array}{l}\text { Stress, } \\
\mathrm{ksi}\end{array}$ & Element \\
\hline $\begin{array}{l}\text { Lower vessel } \\
\text { wall }\end{array}$ & 0.017 & 11.0 & 4318 \\
\hline Supporting leg & 0.004 & 20.0 & 4404 \\
\hline
\end{tabular}

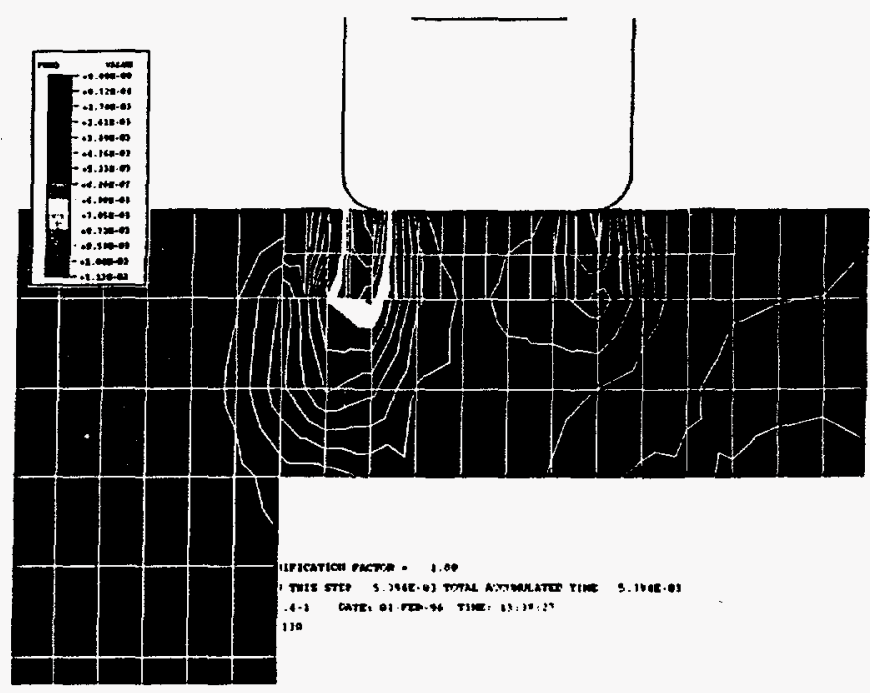

Fig. 3. For the two-dimensional model, permanent damage of the concrete slab at the bottom of the HFIR pool and underneath the surface of impact due to the GE cask expressed in terms of equivalent plastic strain at time equal to $0.0054 \mathrm{sec}$.

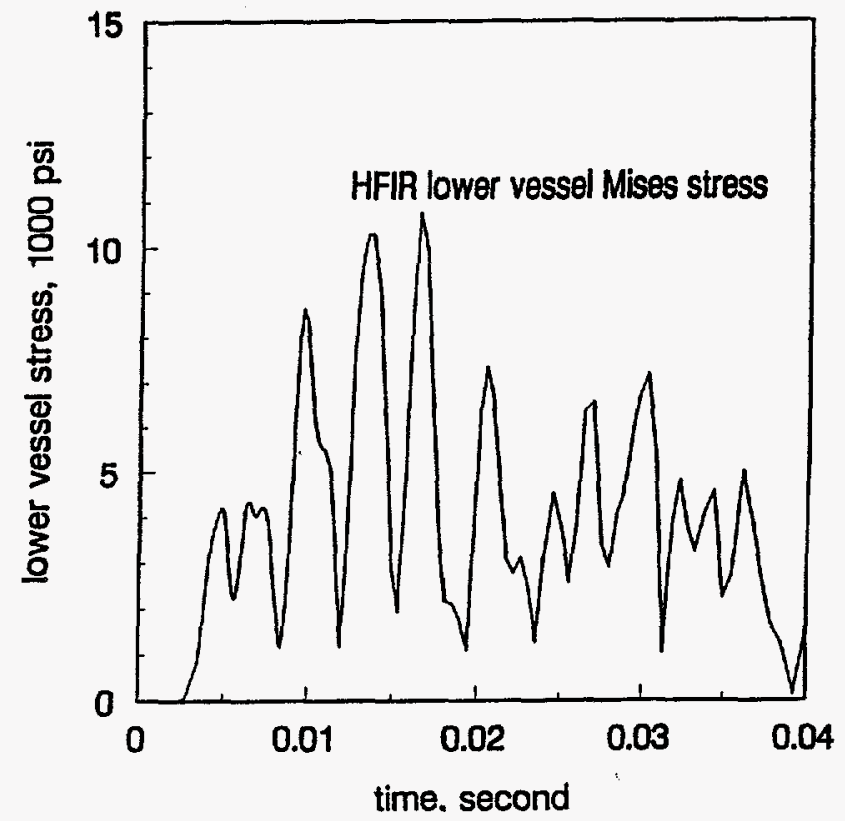

Fig. 4a. For the two-dimensional model, the time histories of the tensile stress (a) for the lower HFIR vessel wall at element 4318 and (b) for the vessel supporting leg at element 4404. 


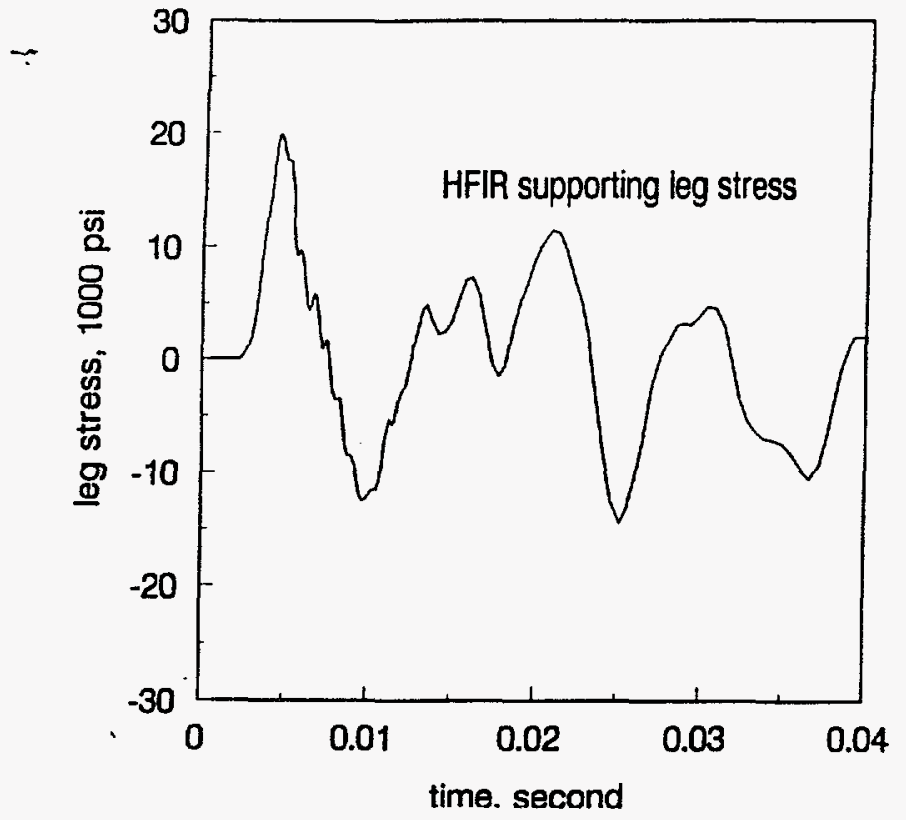

Fig. 4b. (continued).

The yield stress is $36 \mathrm{ksi}$ and the $20 \mathrm{ft}$ drop will not damage the vessel and its legs.

\section{d. Time history solution of the responses at the surface of HFIR base slab}

At the surface of the concrete slab where the HFIR reactor is located, the time history solution of the horizontal and vertical accelerations at node point 785 are shown in Figures $5 \mathrm{a}$ and $5 \mathrm{~b}$, respectively. Node point 785 is located on the surface of the concrete slab close to the lower vessel wall. It is observed that at the very early time, high frequency acceleration waves are generated at the wave fronts for both the horizontal and vertical components. It is a characteristic feature for the impact solutions.

\section{e. Floor velocity response spectrum}

The acceleration time histories shown in Figs. 5a and $5 \mathrm{~b}$ are numerically integrated by using the following convolution integral:

$$
x(t)=\frac{1}{\omega \sqrt{1-\zeta^{2}}} \int_{0}^{t} a\left(t^{\prime}\right) \exp \left[-\zeta \omega\left(t-t^{\prime}\right)\right] \sin \left[\omega \sqrt{1-\zeta^{2}}\left(t-t^{\prime}\right)\right] d t^{\prime}
$$

In the above equation, $\omega$ is the circular natural frequency of a simple one degree of freedom oscillator, $\zeta$ is the damping ratio, and $a(t)$ is the ground acceleration time history. The equation of motion is:

$$
\ddot{x}(t)+2 \zeta \omega \dot{x}+\omega^{2} x=-a(t)
$$

The velocity spectrum is the maximum value of the integral $x(t)$ over the time interval vs the natural frequency $f$ defined as $\omega / 2 \pi$. The horizontal and vertical spectra are plotted in Figs. $6 a$ and $6 b$, respectively.

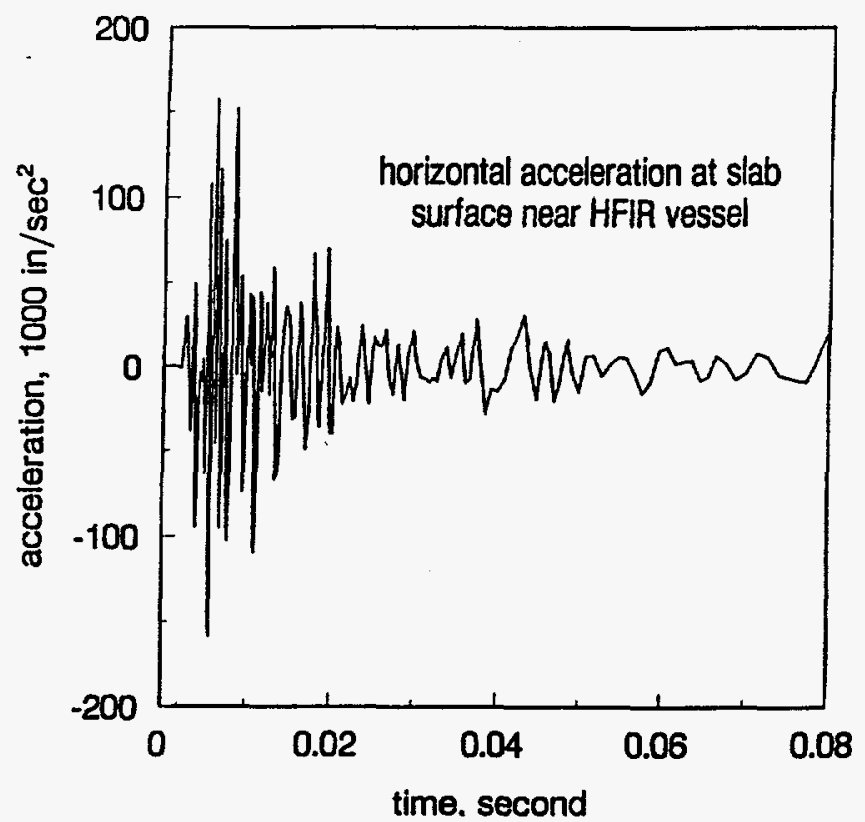

Fig. 5a. The time histories for a point at the surface of the reactor supporting concrete slab near the HFIR lower vessel wall at node 785: (a) horizontal acceleration, and (b) vertical acceleration. High frequency acceleration waves are observed near wave front shown in both (a) and (b).

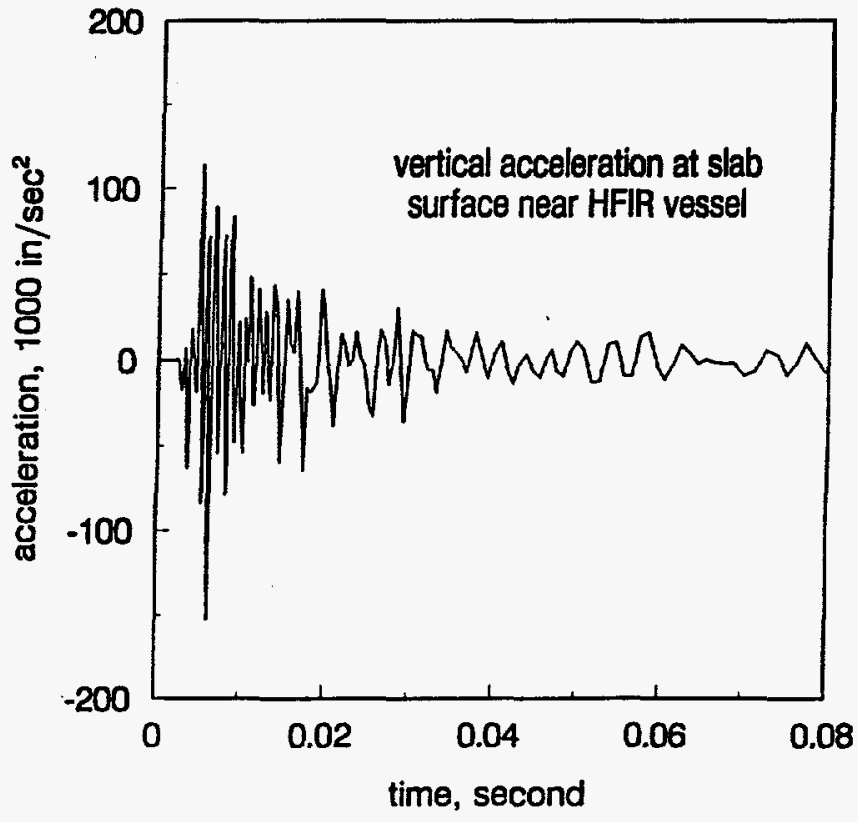

Fig. 5b. (continued)

2. Interpretation of the impact generated response spectra

It is observed that both velocity spectra shown in Figs. $6 a$ and $6 b$ have the magnitude of approximately 10 in/sec. The same order of magnitude is shown in the newly established Oak Ridge Spectrum (Fig. 7) with $0.26 \mathrm{~g}$ peak ground acceleration and $5 \%$ damping. This means that the response spectrum generated by this impact has the intensity that is not more than the design spectrum that is 
- required by the DOE standard. The purpose of the formulation of the Oak Ridge spectrum is to comply with the requirement of the DOE Standard, DOE-STD-1020-1994.

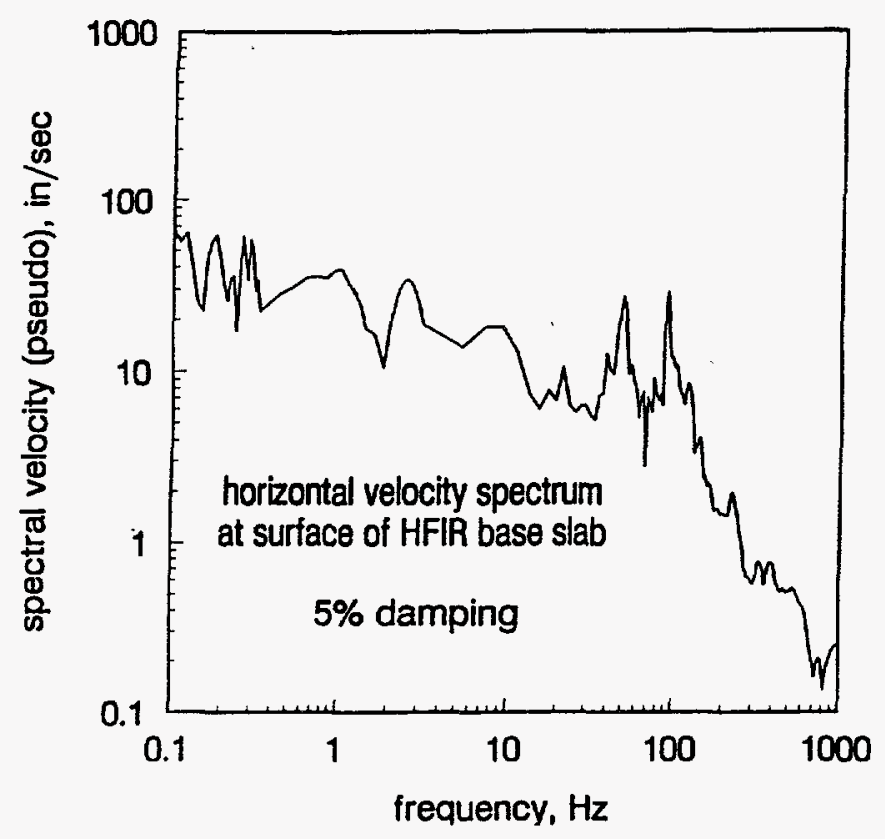

Fig. 6a. (a) Horizontal velocity response spectrum and (b) vertical velocity response spectrum for the twodimensional impact model at node 785 near the HFIR lower vessel wall on the surface of the concrete slab.

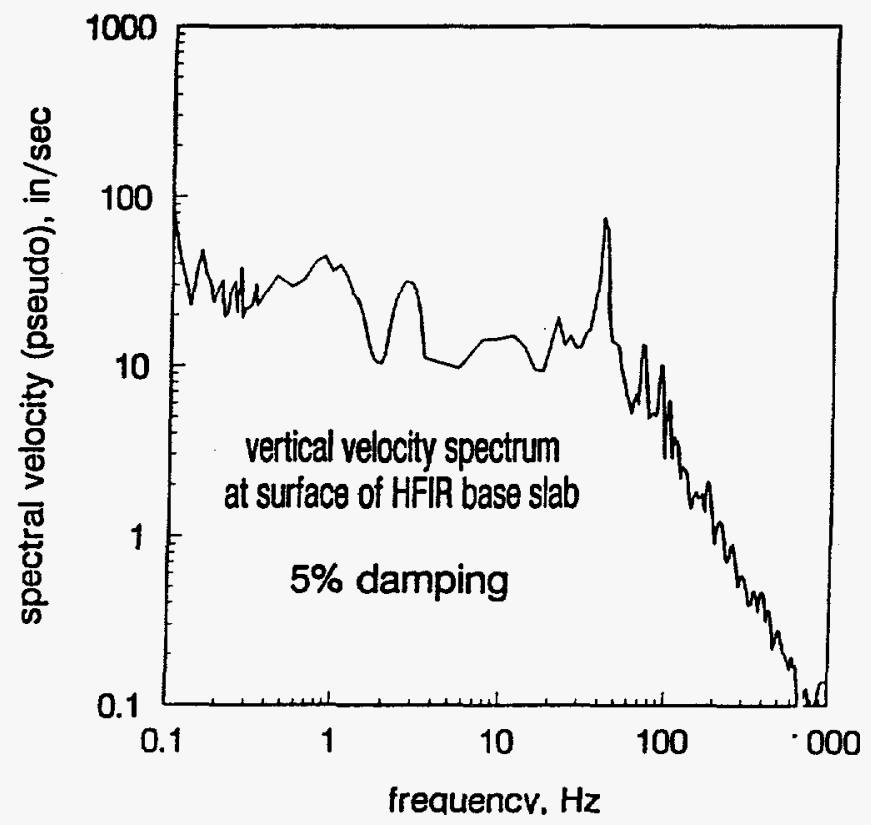

Fig. 6b. (continued)

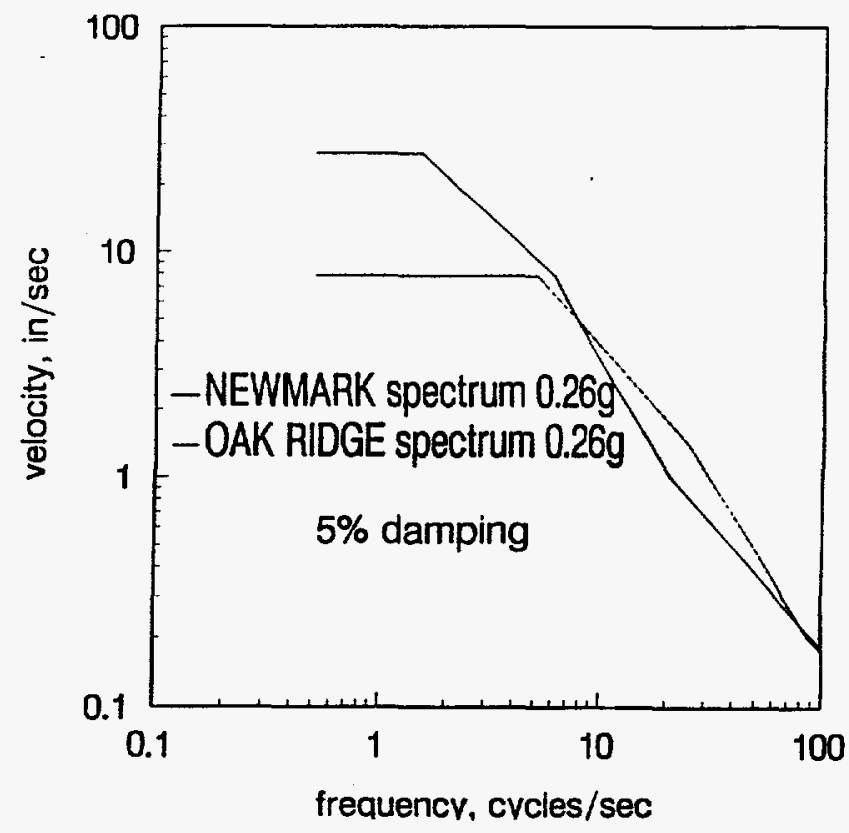

Fig. 7. Oak Ridge spectral velocity response spectrum with $0.26 \mathrm{~g}$ peak ground acceleration and $5 \%$ damping and the corresponding Newmark spectral velocity response spectrum. The maximum spectral velocity for the Oak Ridge spectrum is approximately 10 in/sec that is approximately equal to the maximum spectral velocity generated by the present impact problem [Figs. 7.6(a)(b].

\subsection{SUMMARY OF RESULTS}

1. The plot shown in Figs. 3 for the damage of the pool bottom concrete slab as a result of the heavy load impact indicates that approximately half of the concrete slab would be damaged after the drop of the GE cask.

2. As shown in Figs. $4 a$ and $4 b$, the impact induced stresses in the lower HFIR vessel wall and in the HFIR vessel supporting leg are both elastic. No damage of either part is expected.

3. The above two results imply that the damage as a result of GE cask drop is controlled by the slab damage described in part 1 shown above.

4. The floor velocity response spectra for Figs. $6 a$ and $6 b$ for the HFIR vessel supporting concrete slab has the magnitude approximately equal to the new Oak Ridge spectrum. The spectral velocity generated by the impact is no more then the design response spectrum. The Oak Ridge spectrum is formulated in compliance with the requirement of the DOE Standard, DOE-STD-1020-94. 


\subsection{CONCLUSION}

The HFIR pool bottom slab damage as a result of $G E$ cask drop is the controlling factor for the damage evaluation in this safety analysis. Both the reactor vessel and the supporting legs are not damaged.

\subsection{REFERENCES}

1. Reinforced Concrete Fundamentals, 3rd edition, by Phil M. Ferguson, Wiley, New York, 1973, pp. 9 and 10.
2. Seismic Failure and Cask Drop Analysis of the Spent Fuel Pools at Two Representative Nuclear Power Plants $(H$. B. Robinson and Vermont Yankee) by P. G. Prassinos, C. Y. Kimura, D. B. McCallen, R. C. Murray/LLNL M. K. Ravindra, R. D. Campbell, P. S. Hashimoto, A. M. Nafday, W. H. Tong/EQE, LLNL and EQE prepared for U.S. NRC, NUREG/CR-1576, UCID-21425, January 1989, p. 7-6.

\section{DISCLAIMER}

This report was prepared as an account of work sponsored by an agency of the United States Government. Neither the United States Government nor any agency thereof, nor any of their employees, makes any warranty, express or implied, or assumes any legal liability or responsibility for the accuracy, completeness, or usefulness of any information, apparatus, product, or process disclosed, or represents that its use would not infringe privately owned rights. Reference herein to any specific commercial product, process, or service by trade name, trademark, manufacturer, or otherwise does not necessarily constitute or imply its endorsement, recommendation, or favoring by the United States Government or any agency thereof. The views and opinions of authors expressed herein do not necessarily state or reflect those of the United States Government or any agency thereof. 